\title{
Interdisciplinary Curriculum Empowers Cognitive Advancement to Solve Real Life Problems
}

\author{
Noha M. Al Husni ${ }^{1} \&$ Naim El Rouadi ${ }^{1}$ \\ ${ }^{1}$ Department of Education, Faculty of Arts and Social Sciences, University of Balamand, Balamand, El-Koura, \\ Lebanon \\ Correspondence: Noha M. Al Husni, Department of Education, Faculty of Arts and Social Sciences, University \\ of Balamand, Balamand, El-Koura, Lebanon. E-mail: nhusnie@gmail.com
}

Received: June 1, 2016

Accepted: June 23, 201

Online Published: August 3, 2016

doi:10.5539/jel.v5n4p34

URL: http://dx.doi.org/10.5539/jel.v5n4p34

\begin{abstract}
Interdisciplinary curriculum supports cognitive development through well planned lessons at early age. This article focuses on a specific experimental study done in 2010 on Grade 7 learners in a Lebanese private school to aid them in empowering their skills and competencies to solve a real life problem. The objective of this experimental study is to prepare students for Grade 10 to create the necessary chemistry between learners and Physics as a discipline. The problematic can be stated as: The synergy of teachers' team work to design an interdisciplinary curriculum implementing ICT in classrooms facilitates the transfer and construction of knowledge and scaffolds learners with necessary skills and competencies from an early age to solve physics problems. The results were very optimistic showing $57 \%$ development of the study group members in comparison with only $10 \%$ for the control group members. Further studies are necessary on larger samples and for longer duration to expose learners to different topics and trace the effect of interdisciplinary curriculum after 4 years.
\end{abstract}

Keywords: cognitive development, competencies, critical thinking, interdisciplinary, teaching physics, real-life problems

\section{Introduction}

The objective of this article is to spot the lights on the importance of the integration between interdisciplinary curriculum and the implementation of ICT (Information and Communication Technology) as an approach to accelerate students' cognitive advancement towards the higher thinking levels as synthesis and critical thinking. An experimental study was done on G7 students in a Lebanese private school on a sample of 89 students (51 study group and 38 control group) and proved productive in 2010. Many challenges were encountered starting from untrained teachers on the use of ICT tools in the classroom to feeling offensive when they are asked to prepare their lessons as one group to believing in the obligatory change that should sweep our traditional teaching methodologies. By the end of the experiment, many teachers were surprised by the tremendous increase of students' interactivity during the sessions, their interest and familiarity with the use of technology in the classroom and the productivity of critical thinking on the topic discussed. All the above were discussed in the thesis written on the experimental study conducted in 2010. The writer of the thesis is a Physics teacher for high school and her objective was to find a reasonable pedagogical solution to increase the cognitive development of learners before becoming G10 students where the physics curriculum requires analysis, synthesis and critical thinking in addition to integration between various previously acquired skills to solve one physics problem.

The story started from the fact that teaching physics is already a problem to teachers and learners. Many attempts have been made to facilitate the job: 5-E cycle (Engage-Explore-Engage-Elaborate-Evaluate), inquiry based, discovery based, problem based, project based, game based and other learning theories to teach science in general and physics in particular. Students suffer from more than one difficulty: ability of integrating between disciplines, the language to understand the problem, lack of analysis and critical thinking skills, in addition to the complex physics concepts themselves. On the other hand, teachers have to combine between breaking all these walls separating students from physics learning and meeting the challenges of teaching the $21^{\text {st }}$ century generations. 
In K-12 grade levels and according to the Lebanese curriculum students study science in Grade 1 and get specialized in Physics as a separate discipline as they reach Grade 7 to continue till Grade 12. Serious and thorough observations to classes revealed the following:

- In grades 7 and 8, students "memorize" Physics rather than discover the facts and understand concepts to reach the theories; in other words students solve physics problems as they apply arithmetic and Algebra in Math without recognizing its concrete meaning and appreciating their values in a real life context.

- In Grade 9, students' and teachers' primary worries are to prepare the students and train them to pass the official exams and consequently no time is left to change the methodology of teaching.

- Students reach G10 or the secondary level with nil experience in analysis and critical thinking; in short they lack for the high levels in Bloom-Anderson Taxonomy. Here the G10 Physics teachers are bumped with this fact and have to deal with it and try to get the best of it and what complicates the situation more is the students' prejudice on Physics learning elaborated over the past three years and consequently, most of the students believe that they cannot achieve in Physics.

The above observations describe clearly and honestly the problem eliminating the doubts behind not considering it seriously. Steven Covey in his famous book "The Leader in Me" hypothesized and proved true that teaching leadership skills at young age as young as preschool level is so successful that inspired the thesis writer to hypothesize for physics teaching: why don't we train our students on the skills and competencies required starting from grade 7 and even at younger age? As a result, a case study was conducted in a private school on a population of 89 Grade 7 students. The challenge was to train students on required skills using interdisciplinary learning with the major discipline not the Physics but Geography. The experimental study problematic can be summarized as: Does this Interdisciplinary approach help the students to grasp the concept? Does it train the students to analyze and think critically more than the traditional methodology?

The hypothesis was to design lesson plans for a week duration in 5 different disciplines to teach one competence following the interdisciplinary approach and implementing ICT in classroom. According to the thesis: "Development of transversal competencies in the middle school using ICT" (Husni, 2010), interdisciplinary approach accounts for cognitive advancement of the learner in a student-centered environment to alleviate the critical and creative thinking of the learner and his/her meta-cognitive skills. Interdisciplinary also accounts for team work synergies and the interactive, collaborative, integrative skills of facilitators and learners.

The challenges behind this hypothesis are plenty; many researchers wrote in favor of the effectiveness of interdisciplinary curriculum but teachers refuse even to give it a try as the change takes them off their comfort zone.

\section{Description of the Experimental Study}

The choice settled on Grade 7 learners since it is the first level learners study physics as a separate discipline. The curriculum for different disciplines were scanned and one of the common areas of study was detected as "the Earth". Based on this choice the writer decided on the topic of "Longitudes" and accordingly the disciplines were selected: Geography as the main discipline and the Computer, English, Arabic, and Math are the other supportive disciplines or the transvers studies to support the main topic of longitudes. The 89-Grade 7 students were distributed into 4 sections as per the school and 2 sections A and B were considered as the control group and the other two sections $\mathrm{C}$ and $\mathrm{D}$ were subject to the experiment or the study group. The writer designed the lessons in collaboration with the teachers of corresponding subjects. Two long meetings took place with all the teachers: one at the beginning of the experiment to choose the topic and the second before applying the experiment in the classrooms.

The experiment timing was after Grade 7 had covered the topic on longitudes; as a result the analysis of results was based on the comparison between the geography grades on the topic before and after the experiment.

The experiment started with a problem situation asking "why Australia starts a new year before Lebanon?" followed by the computer session (pre-requisite for Arabic and Geography) whose objective is to teach the learners how to search for authentic information by using the search window and visiting and comparing different web pages results. By the end of the session learners have to fill in the values of longitudes for 6 cities of designers' choice: 1) Cordova-Alaska, 2) Reykjavik-Iceland, 3) Johannesburg-South Africa, 4) Jakarta-Indonesia, 5) Beirut-Lebanon, 6) Greenwich-London.

Then, the other subjects Math, Arabic and English can run parallel before the Geography lesson. During the Math sessions three skills were targeted as the objectives. There are 360 degrees in every circle, how to use the 
protractor to measure angles, and the concept of oriented axis showing the positive direction on the axis and consequently the negative direction is its opposite. During the Arabic session, a text written by the designer narrates a discussion between members of the same family, who live in Beirut, where to spend their vacation and the 5 cities Cordova, Reykjavik, Johannesburg, Jakarta, and Greenwich were the subject of discussion indicating their longitudes and latitudes relative to Beirut so that they can foresee the jet lags and the differences in weather and seasons. The Arabic teacher had to work on the text under narrative writing and its characteristics in addition to grammar, vocabulary, and text analysis and synthesis. The English teacher used two pieces: one a poem and the other a text describing the Earth and its spinning around the Sun and the four seasons during one year under the topic of descriptive texts. Finally comes the Geography lesson about longitudes. All the lessons were presented in the study group classes using computers and LCD projector which turned the classrooms into active and interactive student-centered classrooms and enriched them with documentary videos on the topics. Technology played the role of virtual demonstrations on longitudes drawn as imaginary lines, how the Earth spins about its axis, and the direction of rotation of the Earth about the Sun. The sessions were videotaped for later observations to draw conclusions and some were conducted in presence of the designer.

On the other hand, the control group sections were studying about the longitudes and the Earth using the material available in the national textbooks and following the traditional methodologies as if it is a re-teaching procedure. By the end of the week, all the students of Grade 7 in the four sections took the same assessment which was designed as a multiple choice and free space to show calculation whenever needed in order to show explicitly how the student approached the problem to solve it (written-think aloud). The design of the assessment followed the different levels of Bloom-Anderson Taxonomy.

The results of the assessment were studied and compared to the grades of learners in Geography and the analysis revealed around $57 \%$ of the students showed progress in knowledge and correct analysis concerning the longitude topic when conducted under interdisciplinary approach implementing ICT while only $10 \%$ progress was recorded for students learning under the traditional approach. The designer concluded that such a progress must not be ignored and further experiments on larger samples and other topics must be done and the progress of the students must be traced over the years until learners finish their Grade 10 level in order to prove the validity of the hypothesis (Husni, 2010).

\section{Originality}

The originality of the topic lies behind three axes: 1) The teachers are transforming their job description from lecturers in teacher-centered classes to become facilitators aiding the student-centered interactive classes. This imposes a change in lesson planning approaches as classes are to be conducted as activities in class distributing the tasks over the students to accomplish the required objectives. 2) The team work of teachers of the same grade level with all its tensions and challenges due to lack of experience in group work field in addition to using ICT in preparing their lessons and implementing ICT tools inside the classrooms. 3) Teachers plans towards accomplishing competencies based on cognitive theory empowering the meta-cognitive skills of learners (Husni, 2010).

\section{Theories Supporting the Design of Experimental Study}

\subsection{Interdisciplinary Approach}

Interdisciplinary is strongly supported by Mansilla (2005); in her Project Zero assessment at the Harvard Graduate School of Education, she defined interdisciplinary as "the capacity to integrate knowledge and modes of thinking drawn from two or more disciplines to produce a cognitive advancement... in ways that would have been unlikely through a single disciplinary means" (Case, Coriden, \& Page, 2005, p. 16).

In addition, Field and Stowe (2002) argue that "interdisciplinarity provides a superior way to achieve desired cognitive outcomes in the areas of critical thinking as well as a variety of affective and developmental outcomes" (Case et al., 2005, p. 6).

Husni (2010), in her dissertation, admits the following definition for interdisciplinary approach: "the complex combination of the interaction, integration, synthesis of knowledge and learning across disciplines in a dynamic learning environment that encourages critical inquiry, meta-cognitive skills, collaboration, and ability to relate and compare perspectives and integrative thinking without excluding the implementation of new technologies or ICT" (p. 30). 


\subsection{Cognitive Theory and Jerome Bruner}

Jerome Bruner declared that "any subject could be taught to any child at any stage of development, if it is presented in the proper manner" (Jerome Bruner, 2009). Also Bruner in his "Theory of Value" explains that personal discovery of the learner and his cognitive growth pass in three successive stages of learning: 1) Enactive stage where students' understanding is developed through active manipulation or simply playing with the material to understand how it works. 2) The Iconic stage where learners can reach mental images of the information. 3) The Symbolic stage where students acquire a mental stage of using abstract ideas to represent the world (Jerome Bruner, 2009).

\subsection{Information and Communication Technology (ICT)}

Implementing ICT is a necessity for the digital native generations despite its complexes due to its dynamic nature of development in addition to becoming a basic pillar in every profession. As a result, it is insufficient to train learners on implementing ICT; it is recommended to teach them how to be creative in implementing ICT and maintaining ambitions of life-long learners.

Since ICT provides a jungle of information on infinite number of web pages, it is time consuming to search for reliable information and benefit from shared creative ideas for activities to inspire teachers as they design their active lessons. ICT is a massive challenge to teachers with very poor experience in using ICT in their classrooms (Husni, 2010).

\subsection{Third Generation of the Activity Theory}

Yrjo Engestrom in his third generation of the Activity Theory suggests a structure to overcome the difficulties and challenges when two activities are running simultaneously in order to achieve expansive learning.

\section{"Third Generation Activity Theory"}

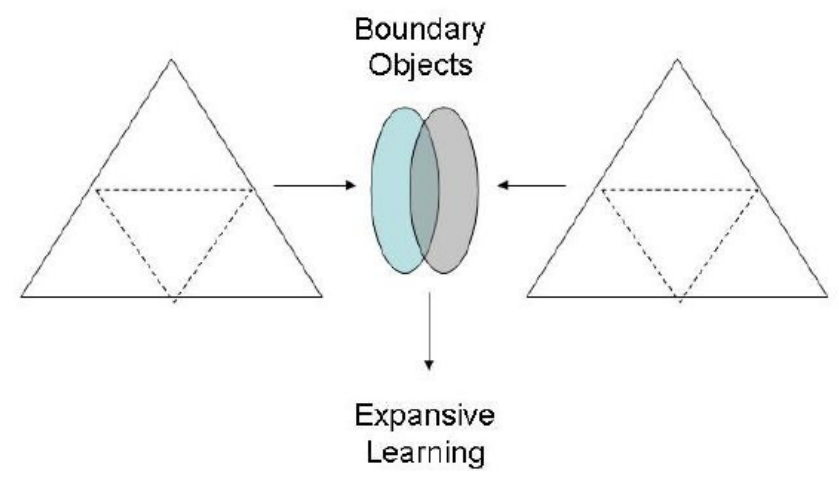

Figure 1. Generation three activity theory (Robertson, 2008) 
Third Generation Activity Theory (Engestrom)

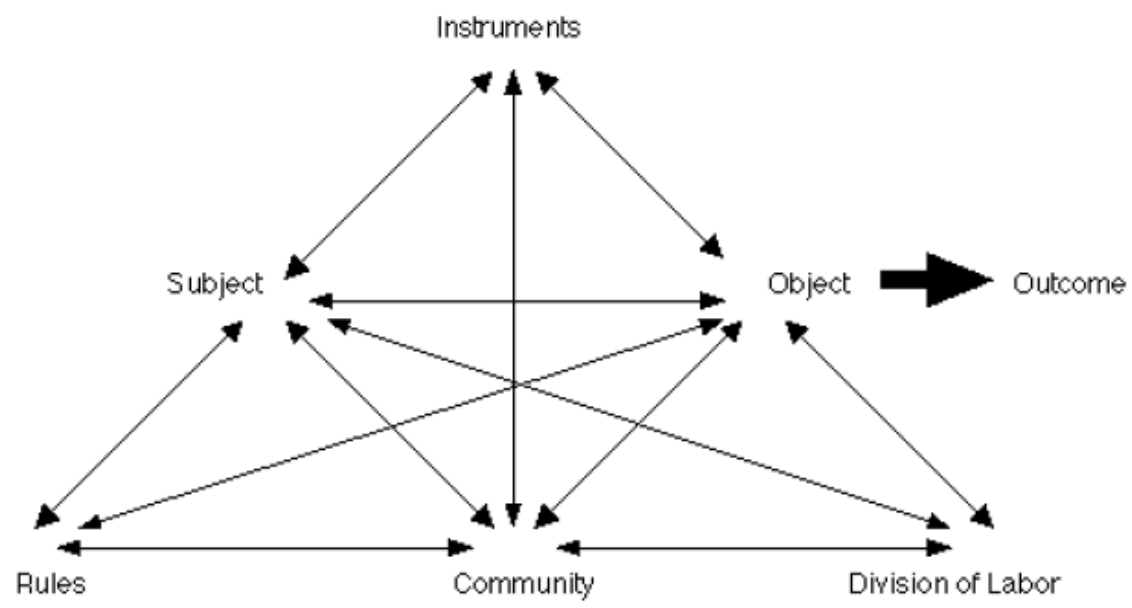

The structure of a human activity system

(Engestrom, 1987, p. 78)

Subject: The individual or group.

The object (or objective): Target of the activity within the system.

Instruments: Internal or extemal mediating artifacts help to achieve the object and then eventually the outcome.

Community: One or more people share the objective with the subject.

Rules: Actions and interactions are regulated by rules within the activity system.

Division of Labor: How tasks are divided horizontally between community members. There is vertical division of power and status as well.

Figure 2. Third generation activity theory (Engestrom-Why Activity Theory, 2002)

The different factors of the scheme in Figure 2 can be interpreted as follows:

- Instruments (tools or artifacts) stand for all media: computers, videos, internet, laboratory experiments, and many times the experts' advice which is mainly the role of the facilitator or teacher.

- The subject stands for learner and/or facilitator who is the person concerned with the cognitive progress.

- The object represents the objectives or direct goals of the activity.

- The outcomes are the competencies the learner is supposed to master by the end of this activity by using the higher levels of thinking and reasoning skills.

- The rules are the constraints and legislations to govern the right path of an activity, a game, or

- The community reflects the participants' backgrounds and ambitions which directly or indirectly affects the validity of the activity.

- Division of labor is the distribution of tasks among the participants in the activity. 


\subsection{Group Work Role}

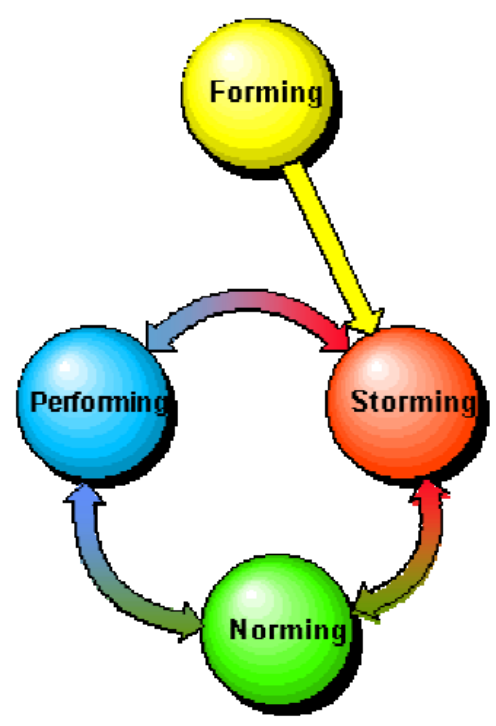

Figure 3. Tuckman's model of group development (Atherton, 2003)

- The Forming stage: [period of uncertainty about norms and roles]. The members might have different levels of commitment to the group work by acting passively, cautiously, and avoid responsibility (Klinger, n.d., p. 29).

- The Storming stage: [management of conflict becomes focus]. The members react with uncertainty about how to deal with issues which makes it the most difficult phase to achieve (Klinger, n.d., p. 29).

- The Norming stage: [establish consensus about roles and norms]. At this stage the group gains momentum as relationships are built with external stakeholders as well as interdependent relationship-building within membership transforming behavior into constructive (Klinger, n.d., p. 29).

- The Performing stage: [period of high effectiveness]. The members take responsibility experiencing high group morale and spirit; consequently, tasks and goals are accomplished with satisfaction (Klinger, n.d., p. 29).

\section{Literature Review}

"In search of Interdisciplinarity in schools in France: From Curriculum to Practice" by Gilles Baillat and Daniel Niclot written in 2010, the authors discuss how "Interdisciplinary processes are being developed for a better present and future in primary and secondary education teaching in France" (p. 170). This movement was triggered by the educational authorities in France over the past few years in order to create new teaching-learning programs for interdisciplinary purposes. They emphasize on the real challenge teachers are facing in implementing interdisciplinary activities. The focus is on "breaking down the barriers between subjects, which must help them acquire the school knowledge useful in social life" (p. 171).

The article points out the resistance attitude towards the interdisciplinary attempt and consequently the need to train in-service teachers on interdisciplinary learning-teaching skills. The study suggests a continuous reformation for teachers as interdisciplinary itself is transforming over the years. An attractive and interesting description for interdisciplinarity was presented by Françoise Cros (1995) as a process of "mutual fertilizing of several subjects".

This article shows the up to date idea of the thesis under study since it matches with the topic discussed by Baillat and Niclot and issued simultaneously in 2010.

Another resource on the topic is "Chapter 5: Interdisciplinary Learning and Interdisciplinary Curriculum". From Knowledge to Action (CAlberta Education, Alberta, Canada issued in 2012. This affirms the momentum interdisciplinary approach is gaining with time as it is still of interest to researchers and experimental studies.

"Grady (1994) noted that poor achievement and low student motivation required educational leaders to seriously consider restructuring school and pedagogy... Interdisciplinary curricula provided patterns and connections for more complex reasoning and enhanced learning by meshing knowledge, skills, and information from different disciplines. She noted that classroom environment, content standards and assessment were essential components 
in developing interdisciplinary curricula. She noted building themes, issues, topics or problems as a way to structure such curriculum. She also noted that interdisciplinary curriculum was a way to organize school in ways antithetical to traditional methods" (pp. 158-159).

In the same resource, a common area between all interdisciplinary programs was summarized to include an increase in understanding, retention and application of general concepts; in addition to viewing multiple perspectives and values for global interdependencies; in addition, interdisciplinary alleviates decision making, thinking critically and creatively, and synthesizing knowledge beyond the discipline. Enhancement of identifying, assessing and transferring significant information to solve new problems were pointed out in the common area too. Interdisciplinary also improved cooperative learning and personal attitude towards oneself and community in addition to increasing motivation (Baillat et al., 2012).

Interdisciplinary approach bridges to workforce relevance. The rapid expansion of ICT helped in morphing disciplines in broad ways. Recently, Bellanca (2010) described the traditional approach of teaching as a "factory model that breaks curriculum into isolated boxes". Drake and Reid in 2010 pointed out that research continuously indicated equal or better academic performance for students in integrated programs versus discipline based programs and students are more engaged and motivated so that they have minimum attendance and behavior problems. And also in 2010 Arts Smarts suggested a model of four interrelated stages of learning:

- Design (learning environment, student centered and proactive).

- Inquiry (Conditions for students to explore, research, and experiment till creativity).

- Expression (integrating skills to creatively communicate learning).

- Reflection (to support deep learning).

Such model can be adopted while designing lesson plans in Physics discipline for all grade levels.

\section{Analysis of the Experimental Study}

\subsection{General Remarks}

Jerome Bruner, Lev Vygotsky and other researchers, while experimenting on different educational topics, agree on the idea that children can learn any idea at early age if it were presented in the correct context. This supports the hypothesis of the thesis writer to start teaching learners the required skills of integrating between different disciplines and approaching real life problems as one entity rather than tackling the problems abstractly and in fragments and pieces (Husni, 2010).

Again, the synergy of team work between the teachers of the same grade level saves the learners all types of redundancy in different disciplines and consequently provides more time to expand on the learning skills, increase the number of skills, and increase the time required by learners to practice more on acquired and recommended skills (Husni, 2010).

Students of the $21^{\text {st }}$ century are the digital natives and they feel at ease when implementing ICT which in turn sets a comfort environment for the learners to be active learners. Using Digitized tools in the classroom in their correct sense with time management provides room for effective student-student and teacher-student interactivity which in turn agitates learners' various skills of engaging, experimenting, exploring, explaining, evaluating, verifying and reconstruction; in brief encourages their critical thinking and creativity (Husni, 2010).

The student-centered approach revealed its effectiveness on learners... Tutors facilitate the students' role in driving their paths to reach the same transversal objectives and competences using different resources through the different levels of reasoning: Perception, Figure/Representation, and Concept (Husni, 2010).

In this paper the third generation of the Activity Theory reflects its expansive learning outcomes and trains the critical thinking of the learners to meet the objectives of the experimental study. "Consider the same example of time difference between New York and Beirut, the learner is supposed to use the mathematical operation she/he built in math class and the research process over the internet on any subject in the computer class to the geography knowledge of longitudinal lines and their relation to time settings. Each is considered as an activity from a different frame; the learner role is to detect that this is the information she/he needs to integrate together to solve the presented problem in the new situation" (Husni, 2010, p. 61).

\subsection{The Conveniences Versus Inconveniences of the Experiment}

Husni in her thesis shared her reflections on the experimental study done: From a positive perspective in spite of all the wide variables that surrounded this experiment, it was feasible to give it a try. Experimentally, observing the recorded videos displays how comfortable, attentive and interactive the learners were while using the 
technology and multimedia in class. In addition, the learners showed ability to interrelate between different disciplines and common objectives and competences. For example, when the Arabic teachers asked for information about the cities mentioned in the text they already collected during the computer class, learners expressed familiarity with the topic and were relaxed in dealing with a new content of the narrative text. Another example is the learners' ability to relate and integrate between math class about axes and circles with the geography about the longitude lines.

The learners were motivated and excited in trying a new approach, although it is not a measurable quantity, but the grade 7 students were reflecting a positive acceptance towards the experiment. On the other hand, the teachers felt for the first time how creative and supportive a group work can be in preparing the lesson plans of one theme. Some of the teachers added to their previous knowledge about the topic. Every teacher knows what other teachers are doing during their classes and they were able to save time in testing for prerequisites of other disciplines; they ask for prerequisites of their subjects only.

There were some inconveniences; for example, "unexpected variables were popping up every now and then during the preparation for the experiment (some teachers do not know how to turn on the computer and this was solved by a volunteer from the students to handle the ICT difficulties in classroom; some teachers do not have a full knowledge of the theme and this was partially resolved during the second general meeting between teachers and designer as the designer presented all necessary prepared work to be projected in classroom and answered teachers' inquiries; some teachers fear what is new, some teachers are overloaded with the regular school duties so they do not have enough time for the preparations... they asked for postponing the experiment.)" (Husni, 2010, p. 101).

\section{Experiment Results}

The experiment divided the students under study into two groups 38 students in control group and 51 students in study group. Upon the students with failing grades (below 65\%) in social studies before the experiment only one student out of ten students showed improvement (grade more than 65\%) in control group by the re-teaching using same traditional methods; in other words a $10 \%$ progress. On the other hand, in the study group eight students out of fourteen with failing grades showed improvement by the experiment approach; it is a $57.15 \%$ improvement.

Such numbers $10 \%$ versus $57.15 \%$ allowed the thesis writer to recommend further studies on the approach in different topics and for longer durations for the same grade level posing a question: If the teachers accepted the new approach and through team work evaluation of first experiment they do the necessary tuning for the new themes trying to avoid the extraneous factors to get more reliable results, would the results remain the same or change?

\section{Synthesis on the Experimental Study}

The experiment as previously explained was designed in an interdisciplinary manner cross meshing concepts from five different disciplines (Computer, Arabic, English, Math, and Geography) and empowered by the suggestions of the teamwork of teachers involved taking their ideas and suggestions into consideration to accelerate the cognitive advancement of the learners through implementation of ICT in the classrooms overcoming any side effects of running simultaneously different activities in different disciplines without distracting the learners' attention from the main objectives of the lessons. Learners were motivated through being in charge of the technology aspect (their comfort zone) in the classroom and the time passed without boredom as the student is continuously busy working on a certain task from an activity or more. Teachers themselves experienced the tensions and synergies of working as a team passing in the forming-storming-norming-performing phases increasing their confidence in implementing ICT in their classrooms and taking the learners as a partner in this process; learning from each other and acknowledging what other teachers are conducting in their classrooms during the same week saved time. Teachers felt the importance of interdisciplinary approach when all are speaking the same language, reducing redundancy, saving time of recalling what skills are needed from other disciplines before starting their lessons. The crucial aspects include the three steps Bruner pointed out: 1) Manipulating with the idea (activities in class, searching the internet, and implementing ICT in class. 2) Representation of the concept (the ICT plays an essential role through video demonstrations and virtually modelling the Earth spinning and the virtual lines representing longitudes). 3) Symbolic stage where the learner deposits the idea and can apply it on an abstract idea. Moreover, the basic relation between what is learned and real life situations which encourages student and teacher to proceed and finish the task. 
The methodology used included both quantitative study and qualitative study. Quantitative through the comparison between learners' social studies grades in study and control group before the experiment and the assessment results of all learners after the experiment. The quantitative study is meant to measure the advancement in cognition of all students and in particular students with social studies grades below $65 \%$.

Qualitative through analysis of video tapes which were recorded in all the classes during all disciplines. Qualitative study reflected through observation the class environment difference with versus without ICT; the learners' engagement in all classes and task, time management concerning learners' analysis of interdisciplinary concepts by realizing what is learned in English and Math for example can be applied in Geography.

Based on the observations during the experimental study, learners were capable of relating between a real-life-question as "You are in Beirut $30^{\circ}$ East and you want to call your friend over the phone. Your friend is in Brazil-Sao Paulo $45^{\circ}$ west. Beirut time is 9:00am; is it a suitable time for you to call your friend?" and using the concept of longitudes to analyze and coming up with a correct answer. Learners in grade 7 who already acquired the competency of looking for a scientific analysis to the question showed evidence of their abilities to construct their individual schemes relating time, geography of the Earth and the longitudes.

After 4 years of the experimental study done on Grade 7 students who passed the Grade 10 level last year, students reminded their physics teacher (thesis writer) of the experimental study which they recall very clearly and this proves that a one week trial left its marks on the students who were under the experiment.

\section{Conclusion}

It is always healthy to expose learners to different learning approaches in attempt to solve long life learning problems as ability to tackle real life physics problems. Every generation have their unique criteria in learning (mentality, tools, audio, visual, kinesthetic...) and consequently requires different techniques of didactics and learning. The thesis under study revealed the importance of integration between different disciplines at early school grade levels in addition to the team work and collaboration between teachers of the same grade level in order to support learners with necessary competencies for their future learning. Since the population under study are very familiar with the digital environment and feel at ease while implementing it within their studies, the thesis proved a successful approach of converting learning to student-centered active approach by admitting interdisciplinary curriculum empowered with ICT.

\section{References}

ArtsSmarts. (2010). 21st century learning. Published by Arts Smarts ISBN 978-0-9782163-4-4. Retrieved April, 2015 from http://www.artssmarts.ca/en/home.aspx

Atherton, J. S. (2003). Tuckman's model of group development. Retrieved April, 2015 from http://www.learningandteaching.info/teaching/group_development.htm

Bellanca, J. (2010). Enriched learning projects: A practical pathway to 21st century skills. Bloomington, IN: Solution Tree Press.

Baillat, G., \& Niclot, D. (2010). In search of Interdisciplinarity In schools in France: From Curriculum to Practice. In Integrative Studies (No. 28, pp. 170-207). Université de Reims, Champagne-Ardenne, France University Institute for Teachers' Training. Retrieved April, 2015 from www.oakland.edu/.../2010\%20Volume \%2028/08_Vol_28_pp_170_207

Case, E., Coriden, T., \& Page, L. ( 2005). Interdisciplinarity: An operational definition and assessment plan: Grinnell College. Retrieved from https://www.grinnell.edu/sites/default/files/documents/Lopatto\%20MAP\%20paper\%20Interdiscipinarity\%2 0Definition\%20and\%20Plan.pdf

Chapter 5. (2012). Interdisciplinary Learning and Interdisciplinary Curriculum (pp. 157-174). From Knowledge to Action (CAlberta Education, Alberta, Canada.

Cros, F. (1995). Interdisciplinarité. In P. Champy, \& C. Etévé (Eds.), Dictionnaire encyclopédique de l'éducation (pp. 585-587). Paris: Retz.

Drake, S. M., \& Reid, J. (2010). Integrated curriculum: Increasing relevance while maintaining accountability. Toronto, ON: The Literacy and Numeracy Secretariat.

Grady, J. B. (1994). Interdisciplinary curriculum: A fusion of reform ideas. Retrieved from http://www.eric.ed.gov/ERICWebPortal/search/detailmini.jsp?_nfpb=true\&_\&ERICExtSearch_SearchValu e_0 $=$ ED375980\&ERICExtSearch_SearchType_0=no\&accno $=\bar{E} D 375980$ 
Halverson, C. A. (2002). Activity Theory and Distributed Cognition: Or What Does CSCW Need to DO with Theories? Netherlands, Kluwer Academic Publishers, Springer.

Husni, N. (2010). Thesis "Development of transversal competencies in the middle school using ICT'. University of Balamand, Lebanon.

Jerome Bruner's educational theory. (2009). Retrieved from http://www.newfoundations .com/GALLERY/Bruner.html

$\begin{array}{lllll}\text { Klinger, } & \text { K. } & \text { (n.d.). } & \text { Followership. } & \text { Retrieved }\end{array}$ http://www.baylor.edu/content/services/document.php/42318.ppt

Robertson, I. (2008). An introduction to activity theory. Retrieved from http://www.ascilite.org.au

\section{Copyrights}

Copyright for this article is retained by the author(s), with first publication rights granted to the journal.

This is an open-access article distributed under the terms and conditions of the Creative Commons Attribution license (http://creativecommons.org/licenses/by/4.0/). 